\title{
Um Esquema para Autoria de Histórias em Mundos Virtuais
}

\author{
Osvaldo Tavares Viana Junior ${ }^{1}$ Alberto Nogueira de Castro Júnior ${ }^{1}$ \\ ${ }^{1}$ Instituto de Computação - Universidade Federal do Amazonas (UFAM) \\ CEP 69.077-000 - Manaus - AM - Brazil \\ osvaldoviana@yahoo.com.br, alberto@icomp.ufam.edu.br
}

\begin{abstract}
Resumo. Este artigo descreve um esquema de autoria em duas fases no qual, num primeiro momento, um terapeuta define elementos como objetos de cena, papéis e ações de uma 'história' utilizando um ambiente (2D) de fácil manipulação para, em seguida, ter esses elementos transpostos para um ambiente de realidade virtual (3D) que poderá ser utilizado pela sujeito da terapia. O esquema proposto foi aplicado ao desenvolvimento de um protótipo onde as ferramentas scratchS4SL e OpenSimulator foram respectivamente os ambientes $2 D$ e $3 D$ utilizados. $O$ 'teatro virtual' foi apresentado a profissionais mediadores (terapeutas) para um ciclo de avaliação formativa no qual ficou evidenciada sua adequação ao propósito e potencial para apoiar a ação junto a crianças com Transtorno do Espectro Autista.
\end{abstract}

\section{Introdução}

A participação em atividades de teatro ajuda na socialização uma vez que produz vários momentos em que a pessoa interage com outras, identificando, analisando e explorando. Tendo em vista que crianças com Transtorno do Espectro Autista (TEA) possuem dificuldades de comunicação e limitada habilidade social, o teatro - mesmo que desenvolvido em um ambiente de realidade virtual - pode tornar-se um importante auxiliar na construção de habilidades e um fator de inclusão da criança.

O desenvolvimento do "Teatro Virtual" teve por meta apoiar a evolução de habilidades sociais, possibilitando que psicólogos, psicopedagogos, fonoaudiólogos e demais profissionais que trabalham diretamente com crianças com TEA tenham auxílio no uso de um ambiente de realidade virtual onde um conjunto de cenários pode ser utilizado para a definição de historias.

\section{Conceitos Básicos}

O autismo pode ser definido sob vários pontos de vista e quando se trata de desenvolvimento das habilidades sociais, é um dos mais conhecidos dentre os Transtornos Invasivos de Desenvolvimento (TID), e de acordo com Sousa e Santos (2013): "O autismo começou a ser descrito por Kanner em 1943, quando o psiquiatra americano começou a agrupar pela primeira vez um conjunto de comportamentos aparentemente característicos, que onze crianças que ele seguia, manifestavam”.

De acordo com Bosa (2006): “o autismo é classificado como um TID que envolve graves dificuldades ao longo da vida nas habilidades sociais e comunicativas além daquelas atribuídas ao atraso global do desenvolvimento e também comportamentos e interesses limitados e repetitivos". Ainda conforme Bosa, a maioria das crianças autistas apresentam dificuldades de compreensão de linguagem abstrata ou dificuldade para lidar com sequencias complexas de instruções que necessitam ser 
decompostas em unidades menores.

Segundo Dubar (1997): “A socialização não é, fundamentalmente, o resultado de aprendizagens formalizadas, mas o produto, constantemente reestruturado, das influências presentes ou passadas dos múltiplos agentes de socialização". Com isso a socialização tende a modificar a forma de interagir do individuo, não permanecendo constante, mas sempre adaptando-se ao ambiente social em que se encontra.

Há técnicas que são utilizadas para atender ao desenvolvimento da interação social do autista, dentre inclusive algumas baseadas no conceito descrito por Lopes e Pavalecki (2013), que afirma: "A memória do autista é voltada para o visual, se faz necessário que o educador em suas técnicas, valorize este lado, fazendo com que o aluno observe cores, tamanhos, espessuras, animais, pessoas... Por outro lado a sala de aula deve ter pouca estimulação visual para que a criança não desvie sua atenção da atividade em andamento.".

\subsection{Terapias e o Papel do Mediador}

O mediador é o profissional responsável para contribuir no desenvolvimento social da criança, e no caso dessa proposta, é o responsável por operar o Teatro Virtual. Em relação ao mediador, Souza et al (2004) relata: “... com sua formação específica e bem definida, deve estar inserido no contexto, sendo também um conhecedor do desenvolvimento humano normal para ter condições de detectar as áreas defasadas e comprometidas. Ele precisa estar muito sensível às observações e relatos da família.". Baseado no contexto desse autor, tem-se que além do mediador, a família também é elemento fundamental no desenvolvimento da criança com TEA. Souza et al descreve o papel do mediador: "O mediador pode influir em vários níveis e desenvolver vários papéis, tais como: investigador e pesquisador, em uma equipe diagnóstica e de avaliação; psicoterapeuta, em uma abordagem individual; psicoterapeuta, em uma abordagem institucional; consultor institucional e orientador familiar.".

Durante levantamento realizado num instituto de suporte a crianças com TEA, a pedagoga da instituição relatou que o papel fundamental do mediador está relacionado em amenizar problemas na escola, auxiliando no seu desenvolvimento na área de socialização, coordenação motora, alfabetização e parte sensorial.

\subsection{Uso da Teatroterapia no Autismo}

Segundo Figueira (2002), “A comunicação não-verbal é o processo pelo qual o sujeito se expressa através de meios que não são da ordem da palavra, um deles podendo ser a linguagem corporal" e também "A linguagem dos corpos nas escolas se modifica a partir da proposta da música, da dança, do teatro, da expressão corporal. São estas linguagens não habituais no contexto escolar que ganham êxito na educação para o autista. Os corpos dóceis se agitam e se movimentam em coreografias criativas. Com isto, o desenvolvimento do grupo começa a se dar através das dinâmicas de grupo.”.

Rocha (2007) afirma: "A dinâmica da Teatroterapia se dá através de jogos dramáticos, trabalhos corporais, técnicas que visam trabalhar o controle da respiração, leitura, discussão e dramatizações de textos teatrais além de improvisações que tem como foco principal situações do cotidiano". Quando aplicado com crianças com TEA, é necessário considerar exercícios simples, operáveis num ambiente virtual, que segundo Madavhan et al (2013) tem como uma de suas vantagens o fato de o usuário 
poder mover-se ao redor do espaço 3D, imitando o mundo real, no qual faz com que através do sistema podemos simular objetos e situações reais. Neste projeto usaremos a plataforma OpenSimulator (comumente referido como OpenSim) em contexto similar ao descrito em Lima e Castro (2012).

Em Pereira et al. (2009) é descrito o ambiente Time2Play, que tem como objetivo a criação ou recriação de histórias conhecidas em ambiente virtual 3D, no qual cada usuário que é conhecido como aprendiz possui um avatar que atuará nas encenações das histórias, onde os avatares podem possuir formas humanas ou nãohumanas, e neste jogo o avatar poderá trocar sua forma a qualquer momento, oferecendo mais liberdade na criação. Ainda conforme Pereira et al. (2009) em seu projeto cada avatar do cenário poderia possuir um inventario contendo objetos, roupas, texturas, animações, sons, entre outras coisas.

\section{O "Teatro Virtual"}

Nossa proposta buscou utilizar o OpenSim para a criação e encenação de histórias, mas para tanto é necessário fluência na linguagem de programação $\mathrm{C \#}$, habilidade pouco provável a um usuário final, como ilustrado na Figura 1. De modo a contornar essa dificuldade, propomos uma estrutura de autoria que utiliza inicialmente um ambiente mais "amistoso" ao mediador, conforme descrito a seguir.

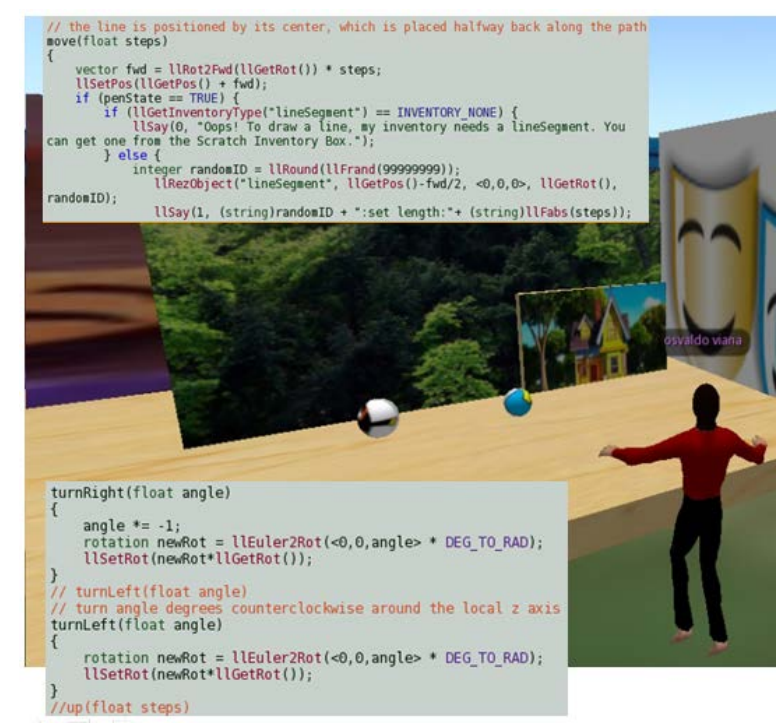

Figura 1: Códigos em linguagem C\# utilizada para movimentos de objetos no OpenSim

Partimos do pressuposto que embora a criança seja o agente final a operar no ambiente, interpretando papéis e experimentando as situações correspondentes, há outros agentes - pais, terapeutas, educadores, cuidadores, técnicos e outros especialistas - responsáveis pela especificação das dinâmicas (encenações).

Conforme mencionado anteriormente, o componente central da proposta é a plataforma OpenSim, um servidor de aplicativos 3D multi-plataforma open-source que pode ser usado para criar ambientes ou "mundos" virtuais (Opensim, 2011) e a busca por um ambiente de especificação de fácil acesso e aderente à metáfora do teatro conduziu à escolha do Scratch, um produto do grupo Lifelong Kindergarten no Media Lab do MIT, fornecida gratuitamente que permite programar histórias interativas, jogos e animações (Scrath, 2007). Utilizamos ainda um ambiente de integração entre o 
Scratch e o OpenSim, que é o Scratch4SL (Scratch For Second Life), que como o nome sugere, foi desenvolvimento originalmente para o ambiente Second Life ${ }^{\mathrm{TM}}$ - o equivalente em versão proprietária do OpenSim. A idéia é que os autores das 'peças' possam utilizar o Scratch para explorar e avaliar diferentes possibilidades (personagens, roteiros, cenários, objetos de cena, etc) e posteriormente transferir módulos de códigofonte gerados no $S 2 S L$ para uso na plataforma OpenSim.

A Figura 2 apresenta um diagrama da proposta onde abaixo da linha tracejada estão ferramentas que foram integradas como componentes do arcabouço e acima da linha tracejada estão representados repositórios construídos e compartilhados pelos autores de histórias, sendo tais elementos operados através de um front-end disponível aos diferentes agentes envolvidos.

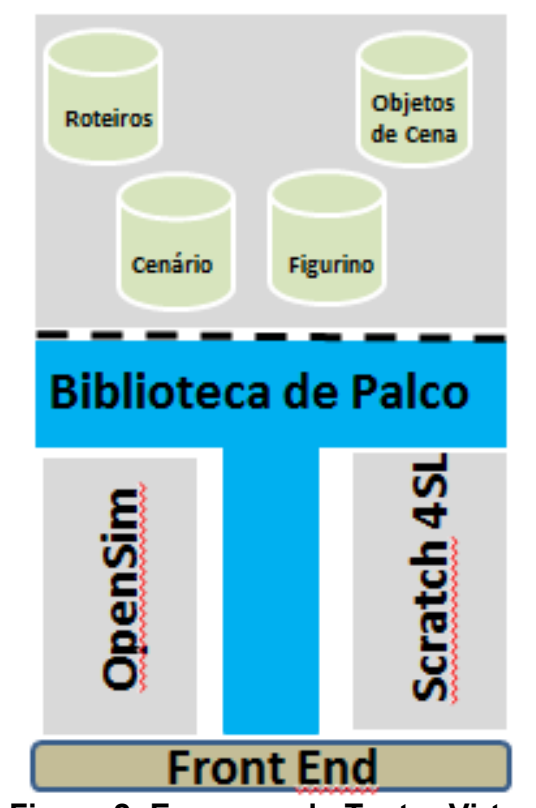

Figura 2: Esquema do Teatro Virtual

Além dos componentes tecnológicos citados, o Teatro Virtual busca encorajar a colaboração em duas frentes: (i) a primeira diz respeito às atividades de autoria de histórias, possibilitando que pais, terapeutas, educadores, cuidadores e educadores construam, analisem e experimentem as situações propostas no Scratch, registrando essa construção coletiva no ambiente, inclusive tendo acesso às experiências similares também registradas ali; (ii) a segunda diz respeito às crianças, cujos avatares estarão interagindo com outros personagens segundo roteiros e situações planejadas.

No Front End o usuário terá acesso a duas ferramentas tecnológicas o OpenSim e o Scratch4SL (ou simplesmente $S 4 S L$ ), na qual primeiro acessará a sala de objetos já existentes no Teatro Virtual bem como os figurinos, e caso não exista nenhum objeto e/ou figurino que seja útil para compor a cena, o mesmo pode importá-lo, cooperando assim para o repositório de objetos de cena e guarda-roupas representado no esquema da Figura 2.

Depois de construída a cena com os objetos no palco do Teatro Virtual, o usuário irá em busca das ações dos objetos em cena, quando será verificado o repositório de roteiros, que são os scripts criados no Scratch4SL. Caso não exista nenhum script que seja do seu interesse, o usuário pode criar um novo script também 
utilizando Scratch4SL, contribuindo assim para o repositório de cenário.

Depois de construído o cenário com os devidos scripts nos objetos, realiza-se testes com a cena, e os ajustes necessários, caso necessário. Feito isso, o usuário começa as atividades com as crianças usando o cenário, fazendo com que a criança interaja com o ambiente operando seu avatar.

\subsection{Contando Histórias}

O workflow do esquema de autoria proposto é ilustrado na Figura 3 através de um diagrama BPMN (Modelo e Notação de Processos de Negócio) BPMN.org (2014). É importante observar no diagrama, que as etapas para utilização do OpenSim somente ocorrem após a execução da história no Scratch funcionar da forma como o mediador a idealizou, como pode ser observado no evento intermediário do diagrama.

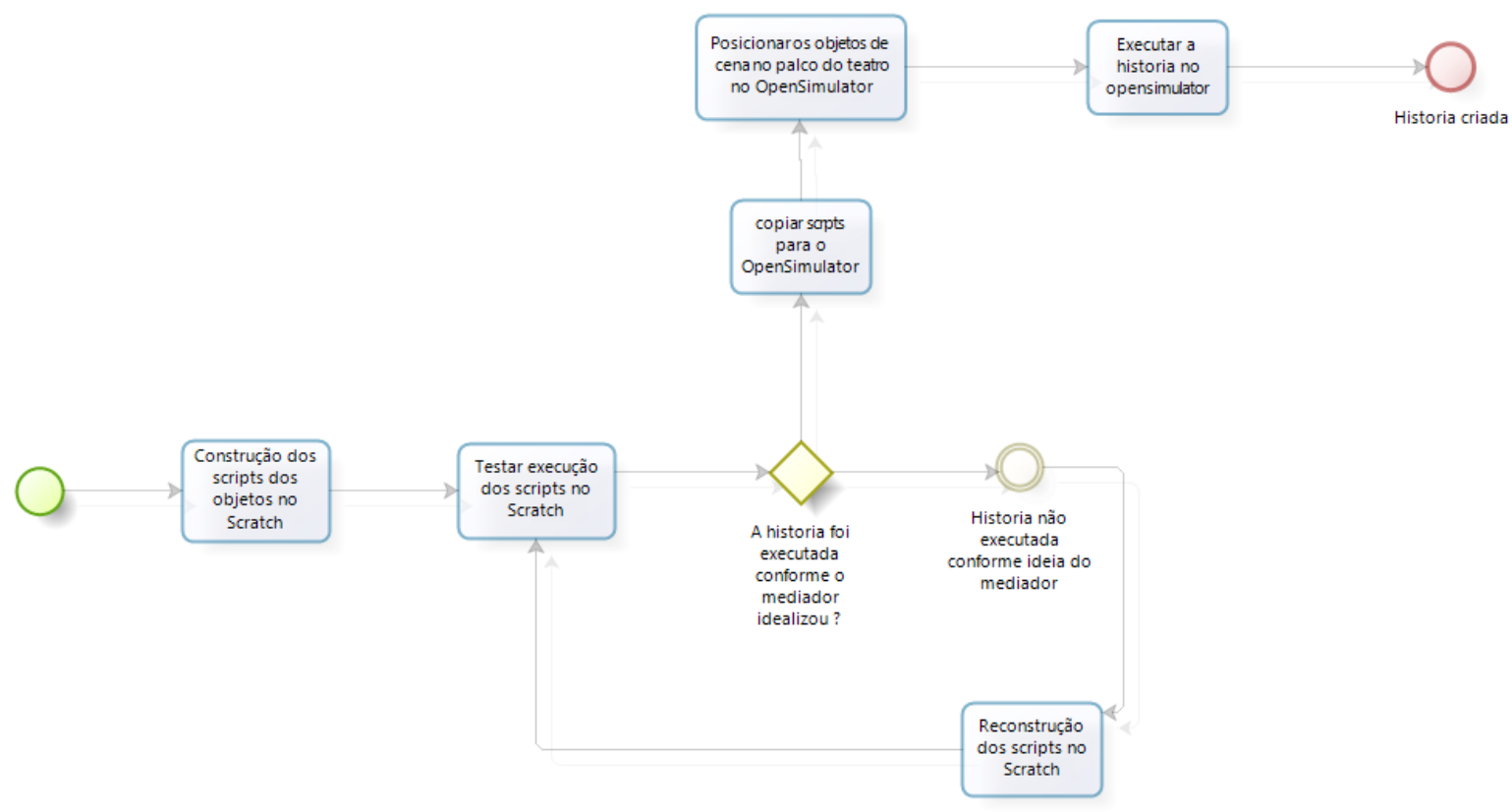

Figura 3: Workflow do esquema de autoria de histórias

\section{Prototipação}

\subsection{Exemplo de Uso: Caça ao tesouro perdido}

Essa história retrata a situação de um tesouro perdido na floresta, na qual um aventureiro (representado por um avatar) tem a missão de encontrá-lo, sem poder contar com o uso de mapas para guiar seu caminho, mas apenas buscando pistas que conduzem até o local do tesouro.

O cenário da história inclui árvore, casa, cachoeira e baús, alguns contendo pistas e num dos quais encontra-se o tesouro propriamente dito. A ideia inicial é explorar o ambiente em busca do tesouro perdido. O cenário inicial da historia pode ser observado na Figura 4, ilustrando o avatar que se encontra no meio da floresta e avista um baú (que pode ser o do tesouro). Um toque no baú apresenta uma mensagem avisando sobre o tesouro [que poderia] estar na casinha amarela, onde há outra pista e assim por diante, até o final da história. 
CBIE-LACLO 2015

Anais do XXVI Simpósio Brasileiro de Informática na Educação (SBIE 2015)

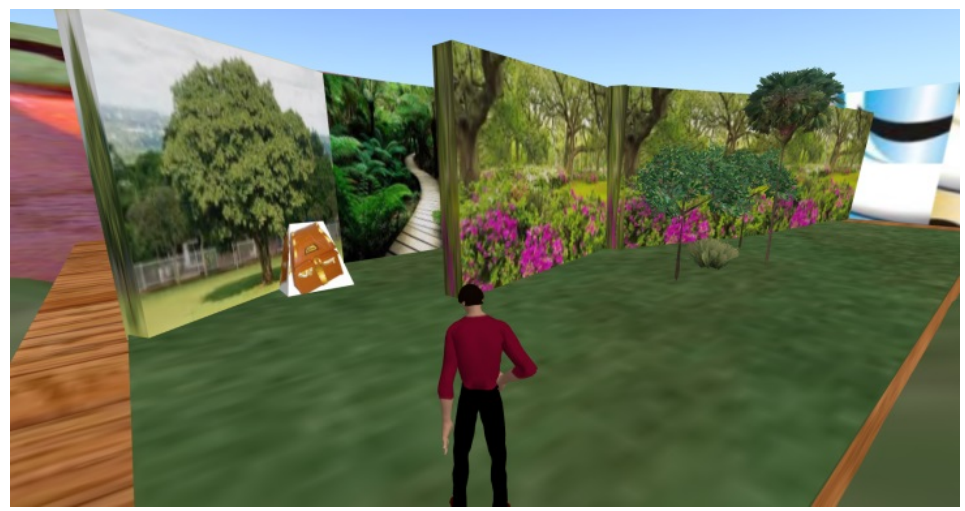

Figura 4: Cenário Inicial da historia

A parte da cena mostrada na Figura 4 que requer a modelagem do objeto baú e da ação correspondente a um toque nele, o que é representado no $S 4 S L$ pela junção de blocos (Figura 5a). Após os testes da representação, essa parte da cena é traduzida para um código em $\mathrm{C} \#$ como o trecho mostrado na Figura $5 \mathrm{~b}$.

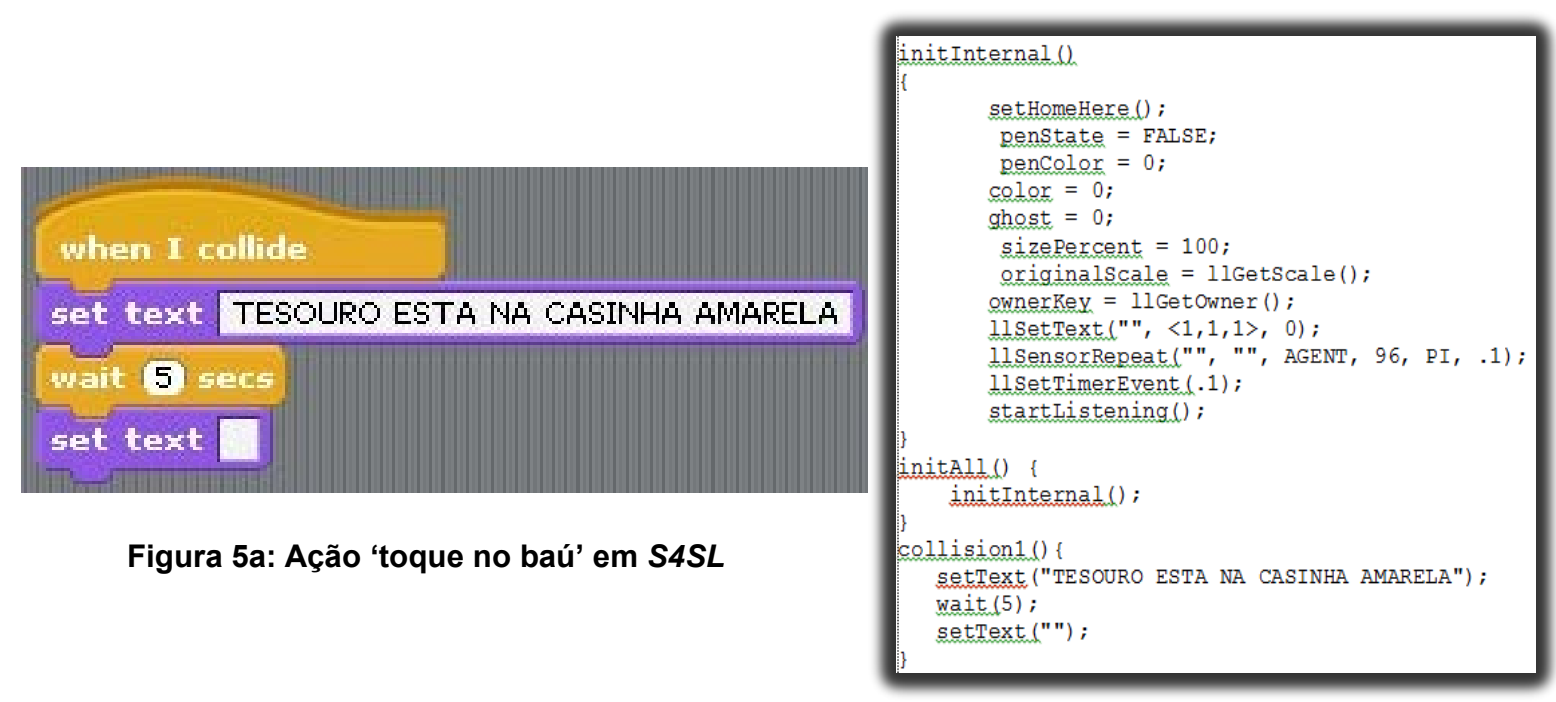

Figura 5b: Parte do código C\# para 'toque no baú'

\subsection{Desenvolvimento do Protótipo}

Depois de concluída a etapa de criação de história com uso do scratch4SL e sua correspondente transposição para o código C\# das ações sobre os objetos, o usuário acessa um conjunto de ferramentas básicas no OpenSim e conclui naquele ambiente, a especificação da história. A Figura 6 apresenta a vista do ambiente no OpenSim onde se pode ver à direita, o controle de objetos. Após selecionados os objetos, é necessário posicioná-los em sua devida marcação de cena no palco, obedecendo a um esquema de associação (vinculo de especificações) que é parte do esquema. 


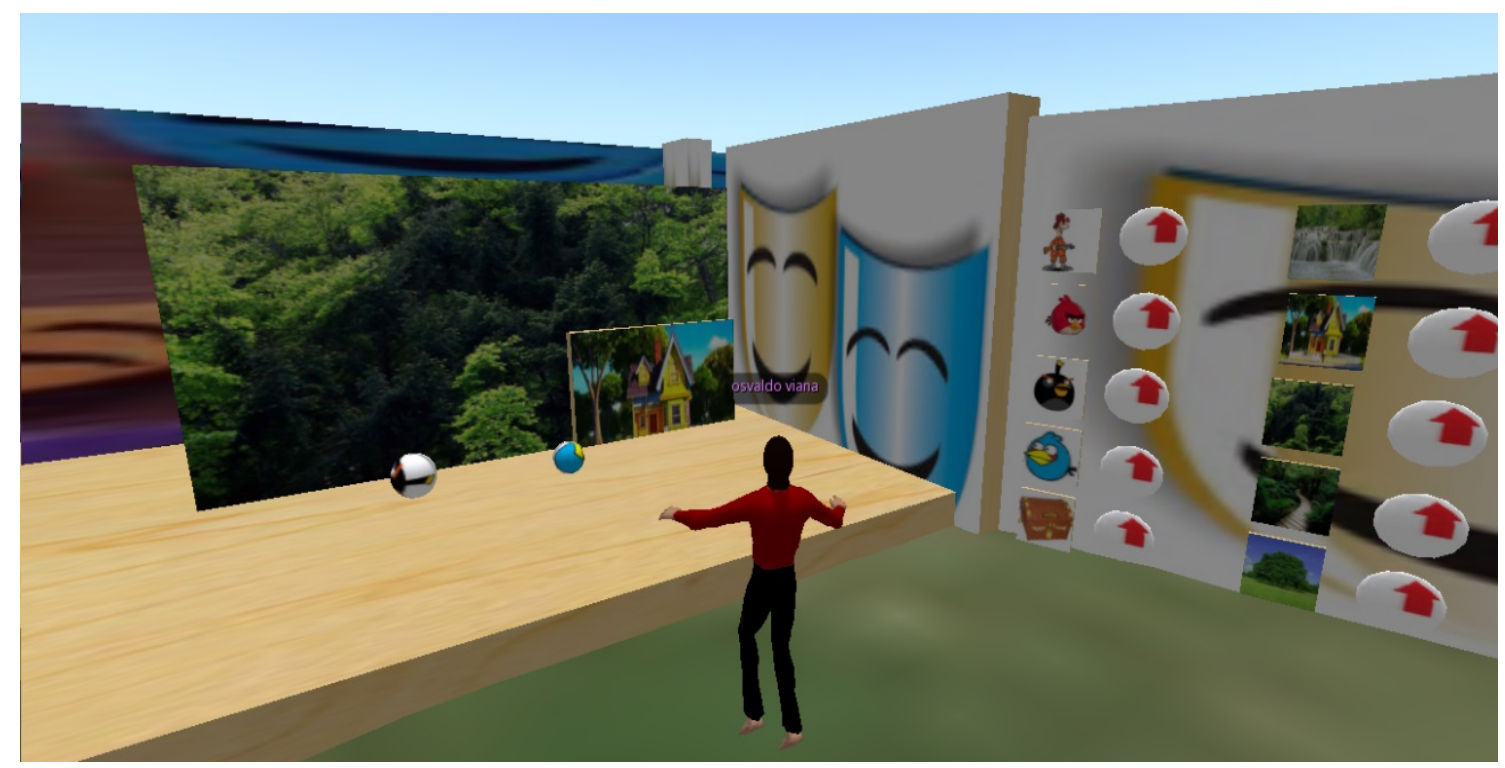

Figura 6: Palco e selecionador de objetos no TeatroVirtual

\section{Prospecção da Usabilidade}

De modo a realizar uma prospecção sobre a usabilidade do protótipo desenvolvido, decidiu-se por utilizar o Percurso Cognitivo, que segundo Salgado (2006, p. 159) "é um método de inspeção de usabilidade que tem como foco principal a facilidade de aprendizagem, particularmente por exploração".

\subsection{Organização do Experimento}

Na Tabela 1 é apresentado o cenário proposto para inspeção do protótipo.

Tabela 1: Cenário proposto para utilizar o ambiente de tradução

\section{Cenário Proposto}

Um Mediador utiliza técnicas de teatro e encenação de historias para auxiliar crianças com TEA em terapia, possivelmente em adição a jogos como LinaEduca e outros recursos. Segundo o Mediador o teatro é uma ótima ferramenta de apoio ao ensaio/preparação da socialização e nesse contexto, o mediador especificará uma historia no ambiente $S 4 S L$ (ambiente 2D) e posteriormente irá transpor essa historia ao ambiente OpenSim, finalizar lá a preparação da história a ser encenada e testá-la.

Os mediadores realizaram as tarefas mostradas na Tabela 2, tendo sido orientados previamente no uso do Scratch e nas características gerais (uso/navegação) do OpenSim.

Tabela 2: Tarefas realizadas para o Percurso Cognitivo

\begin{tabular}{|l|l|l|l|}
\hline Tarefas & \multicolumn{1}{|c|}{ Passo 1 } & \multicolumn{1}{c|}{ Passo 2 } & \multicolumn{1}{c|}{ Passo 3 } \\
\hline $\begin{array}{l}\text { Criar historia } \\
\text { no Scratch }\end{array}$ & $\begin{array}{l}\text { Selecionar os } \\
\text { objetos de cena. }\end{array}$ & $\begin{array}{l}\text { Criar script para cada } \\
\text { objeto. }\end{array}$ & $\begin{array}{l}\text { Executar a ação da } \\
\text { historia. }\end{array}$ \\
\hline
\end{tabular}


CBIE-LACLO 2015

Anais do XXVI Simpósio Brasileiro de Informática na Educação (SBIE 2015)

\begin{tabular}{|l|l|l|l|}
\hline $\begin{array}{l}\text { Traduzir a } \\
\text { historia para } \\
\text { ambiente 3D }\end{array}$ & $\begin{array}{l}\text { Copiar o script do } \\
\text { objeto. }\end{array}$ & $\begin{array}{l}\text { Selecionar o objeto no } \\
\text { OpenSim e colar o } \\
\text { script no mesmo. }\end{array}$ & $\begin{array}{l}\text { Executar a ação do } \\
\text { objeto no ambiente 3D } \\
\text { e retornar o objeto } \\
\text { para o camarim. }\end{array}$ \\
\hline $\begin{array}{l}\text { Executar a no } \\
\text { historia no } \\
\text { ambiente 3D }\end{array}$ & $\begin{array}{l}\text { Selecionar o objeto } \\
\text { desejado } \\
\text { controle de escolha } \\
\text { de objetos. }\end{array}$ & $\begin{array}{l}\text { Posicionar os objetos } \\
\text { no palco em sua } \\
\text { devida posição para } \\
\text { iniciar a encenação. }\end{array}$ & $\begin{array}{l}\text { Executar a historia no } \\
\text { ambiente 3D. }\end{array}$ \\
\hline
\end{tabular}

Para realizar o percurso cognitivo no ambiente de tradução foi selecionado uma historia curta com elementos previamente enumerados, fazendo com que o mediador apenas crie no Scratch e faça a tradução para o ambiente 3D. A execução foi precedida da aplicação de um questionário para caracterização do perfil do usuário e seguida de uma entrevista para a confirmação e aprofundamento de observações.

\subsection{Questionário de Perfil}

Partimos do principio de que o questionário de perfil "destina-se a obter informações sobre as características reais dos usuários de um software, ou aplicação web, e saber como eles efetivamente usam tais ferramentas" (Cybis et al. 2007, p.122).

Cinco mediadores em um instituto de suporte a crianças com TEA participaram da avaliação. Segundo Preece et al. (2008, p. 426), tomadas certas precauções com a escolha dos participantes, mesmo utilizando amostras menores, designers de interação conseguem respostas às questões centrais levantadas sobre o perfil dos mediadores em relação ao uso de recursos tecnológicos no seu cotidiano.

Com a aplicação do questionário foi constatado que todos os participantes usavam o computador diariamente, prioritariamente para fins profissionais, embora também para fins pessoais, acesso a redes sociais, pesquisas acadêmicas, jogos de forma geral e acesso a notícias. Ferramentas de entretenimento e o pacote "Office" foram os recursos mais utilizados no apoio a terapia.

Também foi lembrado que o uso de jogos contribui no auxilio da comunicação, escrita, memorização, imaginação e outros fatores relacionados a socialização, bem como na preparação para atividades de rotina diária.

\subsection{Percurso Cognitivo do Teatro Virtual}

No primeiro momento foi apresentado a ideia do projeto, o esquema e as ferramentas envolvidas. Com isso, os mediadores tiveram acesso ao esquema e de como proceder na criação dos scripts de cada personagem envolvido na história. $\mathrm{Na}$ ocasião, dois dos cinco mediadores manifestarem algumas dúvidas operacionais e já apresentaram sugestão de funcionalidades.

Após a apresentação, foi exposta uma história com os devidos scripts dos atores, sendo solicitado que o usuário experimentasse realizar mudanças nos scripts utilizando o Scratch4SL. A Figura 7 mostra o usuário usando o esquema de autoria do teatro virtual. 
CBIE-LACLO 2015

Anais do XXVI Simpósio Brasileiro de Informática na Educação (SBIE 2015)

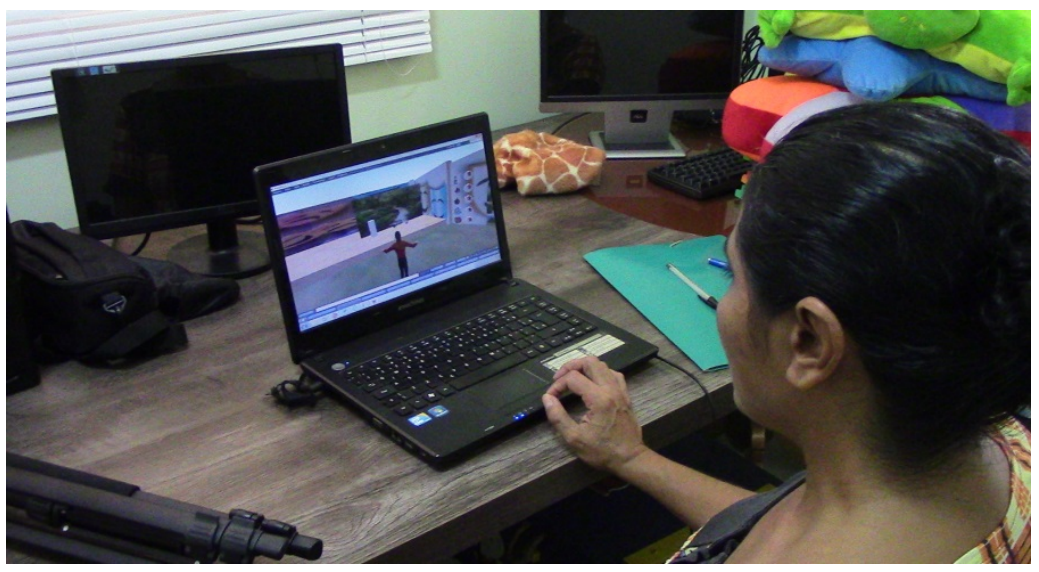

Figura 7: usuário utilizando o esquema de autoria

Para realizar as mudanças na história foi necessário obter o conhecimento sobre associações dos scripts, apresentadas como etapas de testes e final, que antecediam a execução da história no OpenSim. Essa fase foi percebida como essencial para sintonizar a história com a terapia a ser desenvolvida.

\subsection{Entrevista}

Após realização do experimento, cada participante foi entrevistado e vários aspectos do processo foram mencionados, como por exemplo o fato que nem todos perceberam de imediato a associação de scripts.

\subsection{Resultados e Discussão}

Os resultados do percurso cognitivo e da entrevista indicam que não houve dificuldade em realizar as modificações na história apresentada, embora um dos participantes tenha mencionado que preferiria que os blocos funcionais do S4SL estivesse em português. Quatro dos cinco participantes mencionaram que a especificação no $S 4 S L$ foi mais difícil que a execução no OpenSim, o que sugere a que o esquema cumpre o objetivo de contornar a necessidade de manipular código-fonte em C\# no OpenSim.

O esquema de autoria em relação ao seu uso na terapia foi bem aceito por todos os mediadores, que afirmaram que tal esquema seria de muita utilidade, possibilitando trabalhar a rotina das crianças e contribuir com aspectos da comunicação oral e visual, além de explorar a criatividade em grupo.

Foi sugerido uma expansão das funcionalidades de áudio, uma vez que trata-se de recurso importante e valorizado pelas crianças. Criar o próprio personagem com aspectos mais próximos de cada criança também foi um aspecto mencionado pelos usuários.

O fato de que a maioria dos mediadores já utilizaram jogos digitais durante a terapia de crianças com TEA, pode ter contribuído para uma expectativa positiva desde a apresentação do esquema de autoria. De qualquer modo, observou-se a confirmação de tal expectativa nos depoimentos e no interesse de todos os participantes em utilizar o recurso tão logo possível no apoio à terapia das crianças com TEA. 


\section{Considerações Finais}

O Teatro Virtual possibilita, através do esquema de autoria que o constitui, o acesso por usuários não programadores a um ambiente imersivo 3D, no qual histórias podem ser definidas e operadas por crianças com TEA. Não obstante os vários refinamentos possíveis e/ou necessários, este relato apresenta uma prova de conceito para a proposta que sugere sua adequação ao propósito. Próximos passos na investigação incluem a ampliação dos repositórios (roteiros, cenários, figurinos e objetos de cena) e simplificação da especificação no $S 4 S L$.

\section{Referências}

BOSA, Cleonice. Autismo: Intervenções psicoeducacionais. Instituto de Psicologia, Universidade Federal do Rio Grande do Sul. Revisão Brasileira de Psicologia, Porto Alegre-RS, 2006.

BPMN.ORG . BPMN Specification. Disponivel em: $<$ www.bpmn.org $>$. Acesso em: $<04 / 11 / 2014>$

CYBIS, Walter. Ergonomia e Usabilidade: Conhecimentos, Métodos e Aplicações. ISBN: 978-85-7522-138-9. São Paulo: Novatec Editora, 2007.

DUBAR, Claude. A Socialização: Construção das Identidades Sociais. Editora: Porto. Porto - Portugal, 1997.

FIGUEIRA, Ana Maria. O Corpo (con) sentido na educação do autista: Em direção a uma política de inclusão. III Jornada de educação Especial, 2002.

LIMA, David; CASTRO, Thaís. Music Spectrum: Um Sistema Colaborativo de Imersão Musical para Crianças com Autismo. Brazilian Symposium on Collaborative Systems, 2012.

LOPES, Daniele; PAVELACKI, Luiz. Técnicas Utilizadas na Educação dos Autistas.

MADHAVAN, Krishna; UPHAM, Jordan; STERRETT, Benjamin; FISHER, John; GOASGUEN, Sebastien. Cross-reality Services for 3D Virtual Environments.

IEEE. OPENSIMULATOR.ORG. What is OpenSimulator ?. 2012. Disponivel em http://opensimulator.org

PEREIRA, Andreia; VEJA, Katia; RAPOSO, Alberto; FUKS, Hugo. Storytelling Imersivo Colaborativo: Time2Play no Second Life. VI Simposio Brasileiro de Sistemas Colaborativos, 2009.

PREECE, Jennifer; ROGERS, Yvonne; SHARP, Helen. Desing de Interação: Além da interação homem-computador. ISBN: 978-85-363-0494-6. Porto Alegre: Bookman, 2005.

ROCHA, Anamélia. Teatroterapia: O Teatro como terapia social, 2007.

SANTOS, Isabel; SOUSA, Pedro. Caracterização da síndrome Autista. O portal dos psicólogos. SOUZA, José Carlos. Atuação do psicólogo frente aos transtornos globais do desenvolvimento infantil. 2004. Disponivel em: < http://pepsic.bvsalud.org/scielo.php?pid=S141498932004000200004\&script $=$ sci_arttext $>$. Acesso em: 11/07/2014 